\title{
Origin of Acetyl Strophanthidin-Induced Ventricular Arrhythmias
}

\author{
Philip O. Ettinger, Judith Calabro, Timothy J. Regan, and Henry A. Oldewurtel \\ From the Department of Medicine, College of Medicine and Dentistry of New Jersey-New Jersey Medical \\ School, Newark, New Jersey 07103
}

A BSTRACT To examine the origin of digitalisinduced ventricular tachycardia (VT), acetyl strophanthidin (AS) $(25 \mu \mathrm{g} / \mathrm{min})$ was perfused into a limited zone of myocardium in intact anesthetized dogs through a catheter placed fluoroscopically in the left anterior descending artery without ischemia. A second catheter in the great cardiac vein sampled venous effluent from this region. His and left bundle branch depolarizations were recorded and bipolar intramural electrograms from endocardial and epicardial sites within the anterior descending region were obtained. No conduction alterations preceded arrhythmia. Cardiac venous $\mathrm{K}^{+}$rose from $3.3 \pm 0.1$ to $4.4 \pm 0.2 \mathrm{meq} /$ liter $(P<0.001)$, indicating egress from the perfused zone. 10 animals (Group 1) were sacrificed 2 min after onset of VT while 11 (Group 2) continued until fibrillation (4-14 min). All showed normal (endocardial $\rightarrow$ epicardial) transmural depolarization during sinus rhythm, but 10/21 demonstrated reversal, usually late during VT, including $8 / 11$ in Group 2. Epicardial activation preceded fascicular activation and QRS. Recordings from the border and circumflex regions in 10 additional dogs (Group 3) demonstrated activation reversal only in the border zone. Myocardial $\mathrm{K}^{+}$was reduced (mean $63 \pm 1 \mu \mathrm{eq} / \mathrm{g}$ ) and $\mathrm{Na}^{+}$increased (mean $41 \pm 2 \mu \mathrm{eq} / \mathrm{g}$ ) in the perfused zone (nonperfused circumflex area $\mathrm{K}^{+} 72 \pm 1, \mathrm{Na}^{+} 33 \pm 1$ $\mu$ eq/g, $P<0.001$ for both); changes were similar in inner and outer ventricular wall. In related experiments, subepicardial injections 'of AS induced activation reversal within the immediate area, similar to recordings during coronary infusion. Reversed transmural activation with early epicardial depolarization suggest VT arises within myocardium; electrolyte gradients between adjacent regions may be causative.

Received for publication: 9 May 1975 and in revised form 5 October 1976.

\section{INTRODUCTION}

Localization of the specific origin of extrasystoles in the intact heart would be of great theoretical and practical importance, but present methodology limits such determination. Epicardial mapping and plunge electrode methods require repetitive unifocal beats for analysis. Isolated extrasystoles cannot be traced after their inscription, and only sustained unifocal ventricular tachycardias and supraventricular arrhythmias with conduction aberrations have been studied with mapping techniques (1-4).

Digitalis-induced ventricular tachycardia is often sustained and unifocal, providing a simple and clinically relevant dysrhythmia for analysis. In vitro studies of myocardial and Purkinje fibers suggest that only the latter spontaneously depolarize in the presence of digitalis (5-7), and the origin of the digitalis arrhythmia in the dog has been ascribed to Purkinje cells on the ventricular endocardial surface $(1,8)$. To study the characteristics of digitalis arrhythmias, we infused acetyl strophanthidin into a limited region of left ventricular myocardium and evaluated the electrical and ionic changes induced. Electrode recordings suggest that epicardial or intramyocardial ectopic pacemakers may be stimulated by regional digitalis infusions; specific changes in myocardial electrolytes possibly are related to the extra-systolic activity.

\section{METHODS}

Healthy male mongrel dogs weighing between 19 and $35 \mathrm{~kg}$ were studied. Premedication was $3 \mathrm{mg} / \mathrm{kg}$ morphine sulfate and anesthesia was induced with $12 \mathrm{mg} / \mathrm{kg}$ intravenous pentobarbital sodium. Dogs were intubated, placed in a left lateral position, and respiration was maintained mechanically. Jugular, carotid, axillary, and femoral vessels were surgically exposed for catheterization. Arterial pressure was continually monitored.

To study intramural conduction, a left thoracotomy and pericardiotomy was performed and the heart suspended in a 


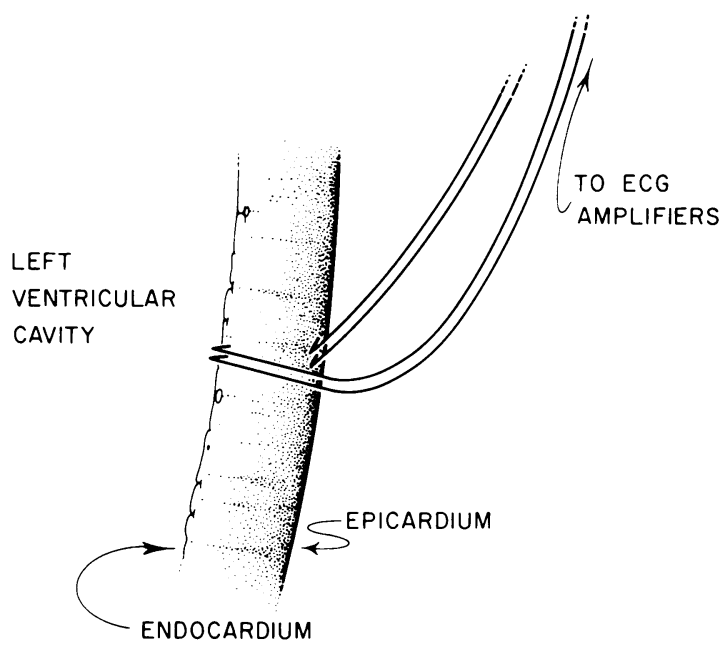

FIGURE 1 Diagrammatic cross-section of left ventricular free wall indicating plunge electrode placement.

pericardial cradle. Bipolar electrodes (9-11) of Tefloncoated (Medwire Corp., Mt. Vernon, N.Y.) stainless steel wires with tips bent into small hooks (uncoated diameter 0.005 inch) were inserted through 21-gauge hypodermic needles into the endocardium and epicardium of the left ventricular free wall (Fig. 1) centrally within the region perfused by the left anterior descending (LAD) ${ }^{1}$ artery, approximately $1-4 \mathrm{~cm}$ from the cardiac apex. One bipolar epicardial electrode and one bipolar endocardial electrode were inserted in each animal in the majority of studies; in later experiments additional epicardial sites were monitored. The endocardial and epicardial sets were placed along an imaginary line traversing the free wall perpendicularly. Each bipolar pair was led through a switchbox into the A-C input of an electrocardiogram (ECG) preamplifier and the electrograms filtered at $0.1-2,000 \mathrm{cps}$ and displayed on an oscilloscopic photographic recorder. After satisfactory electrode placement, as evidenced by a single sharp deflection often followed by some ST-segment displacement, the chest was closed and the animal allowed to recover for 1-2 $\mathrm{h}$ until injury disappeared from the electrograms. The peak of the rapid deflection was accepted as the moment of activation at that site. While on occasion additional slow activity reflecting more distant activation was recorded, most electrograms demonstrated a single sharp peak for measurement. In a few experiments, the $\mathrm{dV} / \mathrm{dt} \max$ of the electrograms were also recorded.

Next, no. 7F Sones catheters (U.S. Catheter Corp., Billerica, Mass.) were fluoroscopically placed in the anterior descending coronary artery and great cardiac vein. The infusion catheter in the coronary artery had an end-hole only, while the venous catheter had end- and side-holes for sampling.

An electrode catheter of the tripolar Castillo type (Electrocatheter Corp., Rahway, N.J.) was preshaped in hot water by curving the tip into a $2-\mathrm{cm}$ loop, then passed via a carotid artery into the region of the right coronary cusp of the aortic valve, where it uncoiled to assume a "J" shape with tip directed anteriorly, and where a His bundle electrogram was recorded. A second Castillo catheter was advanced into

${ }^{1}$ Abbreviations used in this paper: AS, acetyl strophanthidin; ECG, electrocardiogram; LAD, left anterior descending. the left ventricle and directed anteriorly to record from the peripheral anterior Purkinje radiation of the left bundle branch (anterior false tendon). Impulses were filtered at 40-500 cycles/s. Recording from the His bundle and bundle branch has been demonstrated by this technique in the $\operatorname{dog}(12,13)$ and in man (14). The bipolar bundle branch electrogram was displayed and recorded simultaneously with the His bundle electrogram, the intramural electrograms, and the peripheral electrocardiographic lead 1 at a speed of $200 \mathrm{~mm} / \mathrm{s}$. To ensure that a portion of the QRS was not isoelectric in that lead, the other two standard leads were recorded sequentially with the electrograms. $\mathrm{H}-\mathrm{V}$ (or $\mathrm{H}-\mathrm{Q}$, the interval from the first rapid deflection of the His bundle complex to the onset of the QRS), H-a (the interval from His to the false tendon complex), and QRS duration were later measured to the nearest $0.1 \mathrm{~mm}$ paper $(0.5 \mathrm{~ms})$, as were intramural activation times and amplitudes.

Coronary blood flow was determined to be normal in every animal after placement of the coronary artery catheter by injection of a saline solution of ${ }^{85} \mathrm{Kr}$ antegrade into the coronary artery and observing the subsequent washout with a precordial scintillation counter. Coronary blood flow was calculated by the relation: coronary blood flow $(\mathrm{ml} / 100 \mathrm{~g}$ per $\min )=0.63 \times 100 / t_{\frac{1}{2}}$, where $t_{\frac{1}{2}}$ is the half-time for decline of radioactivity.

Blood hematocrit, $\mathrm{pO}_{2}$, and $\mathrm{pH}$ were determined to be normal before study. Duplicate samples of arterial and coronary sinus blood were drawn in heparin, control pressures and electrical events recorded, and an infusion of acetyl strophanthidin (AS, $25 \mu \mathrm{g} / \mathrm{min})^{2}$ begun into the coronary artery. Arterial and great cardiac vein samples were taken at 2, 4, 6, 8,12 , and 16 min or until ventricular fibrillation occurred; the duration of infusion ranged from 6 to $16 \mathrm{~min}$. Ventricular tachycardia always began from 2 to 6 min after the onset of infusion. To evaluate both the early (ventricular tachycardia) and late (ventricular fibrillation) stages, we arbitrarily terminated the study in 10 animals 2 min after the onset of ventricular tachycardia (Group 1). 11 animals continued until ventricular fibrillation (Group 2), 4-11 min after ventricular tachycardia began (mean $7 \mathrm{~min}$ ).

To evaluate the activation sequence within the (nonperfused) circumflex region during drug perfusion of the anterior descending artery, 10 other dogs had endocardial and epicardial electrode pairs placed within the circumflex region in a similar manner. These animals comprise Group 3 and include three dogs with electrodes near the anatomic epicardial boundary of circumflex and anterior descending regions and seven with implantations more than $1 \mathrm{~cm}$ within the circumflex zone. All these animals continued until ventricular fibrillation.

At the end of all 21 studies in Groups 1 and 2, the hearts were quickly removed by thoracotomy $(1 \mathrm{~min})$ and placed in iced Ringer's solution. A full-thickness segment of left ventricular free wall from the center of the perfused region and including the plunge electrode site was removed and rapidly divided by sharp dissection into equal inner, middle, and outer thirds, each about 3-mm thick and weighing 1-2 g. A similar segment was taken from the nonperfused circumflex region and prepared in the same manner. The layers were subsequently analyzed for potassium and sodium (15) content. Tissue water was determined by weight differences before and after oven drying of a tissue homogenate overnight at $110^{\circ} \mathrm{C}$. In 12 normal dogs studied during the same period, myocardial water and electrolytes were determined for comparison. (No differences in tissue composition

\footnotetext{
${ }^{2}$ Generously supplied by Dr. G. C. Chiu, Eli Lilly and Company, Indianapolis, Ind.
} 


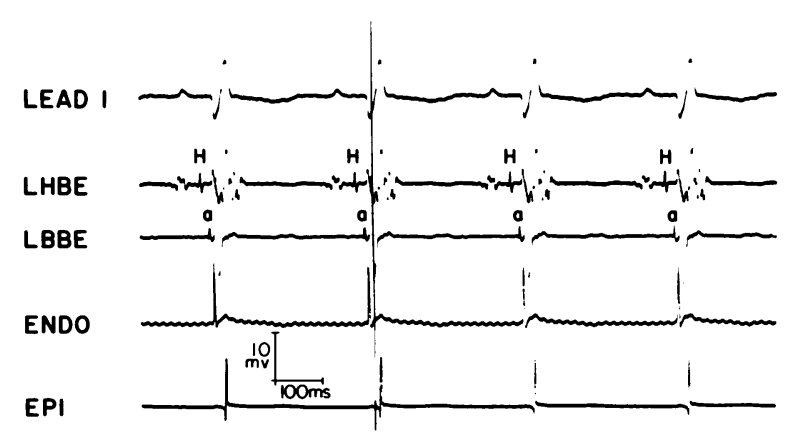

FIGURE 2 Control record showing electrograms. From above, ECG lead 1, His bundle electrogram recorded from aortic root (LHBE), left bundle branch electrogram (LBBE), endocardial (ENDO) and epicardial (EPI) electrograms from the anterior descending region. " $\mathrm{H}$ " and "a" indicate His and anterior false tendon recordings. Time lines $1 / s$, paper speed $200 \mathrm{~mm} / \mathrm{s}$. Voltage calibration is for electrograms only.

were found in other studies comparing sham operated and intact control dogs.) Tissue analyses were not performed in Group 3.

As the drug solvent is $25 \%$ ethyl alcohol (diluted to $2.5 \%$ and infused at $0.5 \mathrm{ml} / \mathrm{min}$ ) and since this substance causes myocardial $\mathrm{K}^{+}$loss when infused intravenously in quantity (16), an equivalent dilution of ethanol in distilled water was infused into the anterior descending artery in three additional dogs for $16 \mathrm{~min}$, equal to the longest $\mathrm{AS}$ infusion time. No arrhythmias were observed and no $\mathrm{K}^{+}$loss was demonstrable in the great cardiac vein.

In related experiments, ventricular arrhythmias were induced in an additional 13 open chest, anesthetized dogs by the subepicardial injection of $100 \mu \mathrm{g}$ AS, mixed with India ink (Group 4). These are further discussed below. To ensure that epicardial injury and (or) the India ink and diluent were not responsible for the arrhythmias observed after intramyocardial injection, 14 epicardial injections were made in three additional dogs, each with $0.3 \mathrm{ml}$ of ink-diluent. The animals were observed for $20 \mathrm{~min}$ after each injection but no extrasystoles were observed.

Statistical analyses were performed by computer with standard techniques for small samples. Mean values for different groups were compared using the unpaired $t$ test; means of differences in the same animals were treated by paired $t$ testing.

\section{RESULTS}

Electrophysiological data. At the onset of the study all animals were in sinus rhythm. A representative recording from the control period is seen in Fig. 2. Each $P$ wave is followed by $\mathrm{His}$ bundle and left bundle branch activation, then onset of QRS and almost simultaneous endocardial depolarization with epicardial activation following $10 \mathrm{~ms}$ later. No alteration of this sequence was observed after the start of infusion, but before the onset of arrhythmia the intramural electrograms were slightly reduced in amplitude in a few animals but unchanged in most. A ventricular arrhythmia, sometimes but not usually unifocal, in-

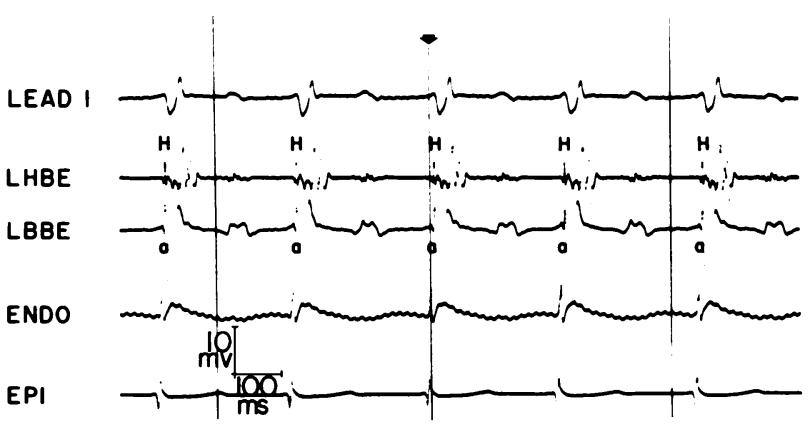

FIGURE 3 Onset of tachyarrhythmia. Labeling as in Fig. 2. The His bundle electrogram follows the onset of QRS by a few ms. The bundle branch recording is simultaneous with LHBE while epicardial activation precedes endocardial and both occur before the beginning of QRS. Arrow indicates QRS onset time.

variably began after 2-6 min. QRS complexes were widened, faster than the underlying sinus rhythm and dissociated from $\mathrm{P}$-wave activity. Slowing of sinus rhythm, usually observed after systemic administration of digitalis $(17,18)$, was not seen. We always observed His bundle depolarizations to occur within or at the beginning of QRS activity from the start of arrhythmia (Fig. 3). The left bundle branch impulse also merged with and never preceded the QRS. The abrupt onset of ventricular tachycardia was usually not associated initially with change in the sequence or timing of endocardial and epicardial activation. In 10 of these 21 dogs (Groups 1 and 2), however, reversal of the normal endocardial-epicardial sequence was observed, often after 4 or more min of arrhythmia (Fig. 3), although reversal was seen from the onset of ventricular tachycardia in two dogs (Table I). 8 of the 11 dogs in Group 2 demonstrated reversal, as did 2 of the

TABLE I

Early Epicardial Activation during Arrhythmia

\begin{tabular}{clc}
\hline \multicolumn{1}{c}{ Group } & $\begin{array}{l}\text { Dogs } \\
\text { showing } \\
\text { reversal }\end{array}$ & Time to fibrillation \\
\hline & & $\min$ \\
1 (Nonfibrillators) $(n=10)$ & 1 at onset & - \\
2 (Fibrillators) $(n=11)$ & 1 at 1 min & - \\
& 1 at onset & 5 \\
& 1 at 1 min & 4 \\
& 1 at 3 min & 4 \\
1 at 5 min & 6 \\
1 at 5 min & 11 \\
1 at 6 min & 8 \\
1 at 7 min & 8 \\
All $(n=21)$ & 1 at 8 min & 9 \\
\hline & 10 of 21 & - \\
\hline
\end{tabular}




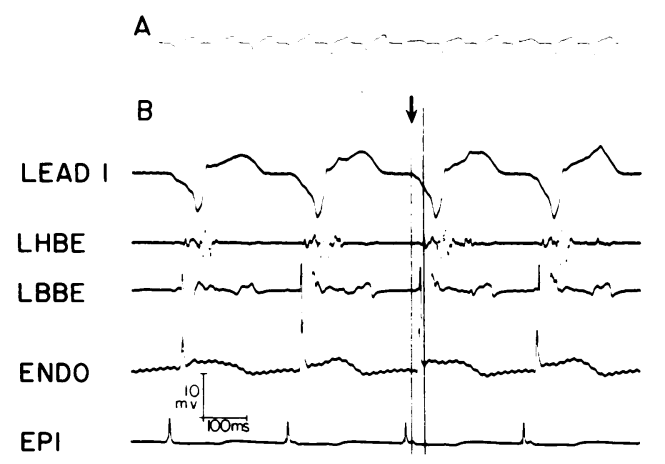

FIGURE 4 (A) 12-beat strip of lead 1 ECG showing slightly varying morphology of ventricular tachycardia. (B) Enlarged view of initial four beats of above strip. An apparent His bundle impulse lies well within the QRS. Epicardial depolarization precedes endocardial and in this instance occurs $16 \mathrm{~ms}$ before QRS onset. Arrow aligns QRS onset and electrograms in the third beat. Electrogram morphology changed between Figs. 4 and 5, suggesting possible differences in direction of wavefront spread of activation. For this reason, it cannot be assumed that a true increase in retrograde transmural conduction time occurred between the two figures. Abbreviations and calibrations as in Fig. 2.
10 dogs in Group 1. In Fig. 3, epicardial depolarization precedes endocardial and the epicardial activation precedes the beginning of the QRS in the monitoring lead. His and left bundle impulses are synchronous with QRS onset but both are perceptibly later than activation at either intramural site. Slightly later (Fig. 4), more obvious reversal of transmural activation is seen during ventricular tachycardia; in addition, epicardial potentials precede QRS onset in the surface ECG by $16 \mathrm{~ms}$. Each QRS varies slightly in configuration and the sequence of endocardial, left bundle, and His bundle activation varies slightly as well; despite some configuration changes the epicardial is the earliest recorded activity in each beat. With additional epicardial electrodes placed $1-3 \mathrm{~cm}$ from the original electrode site it was sometimes possible to record early epicardial activation at more than one site (Fig. 5). This was interpreted as evidence that a broad segment of the perfused region was activated early and that the site of origin of the rhythm disturbance might change from beat to beat. Probably for this reason the stable repetitive tachycardias seen after intravenous administration of digitalis were not regularly observed
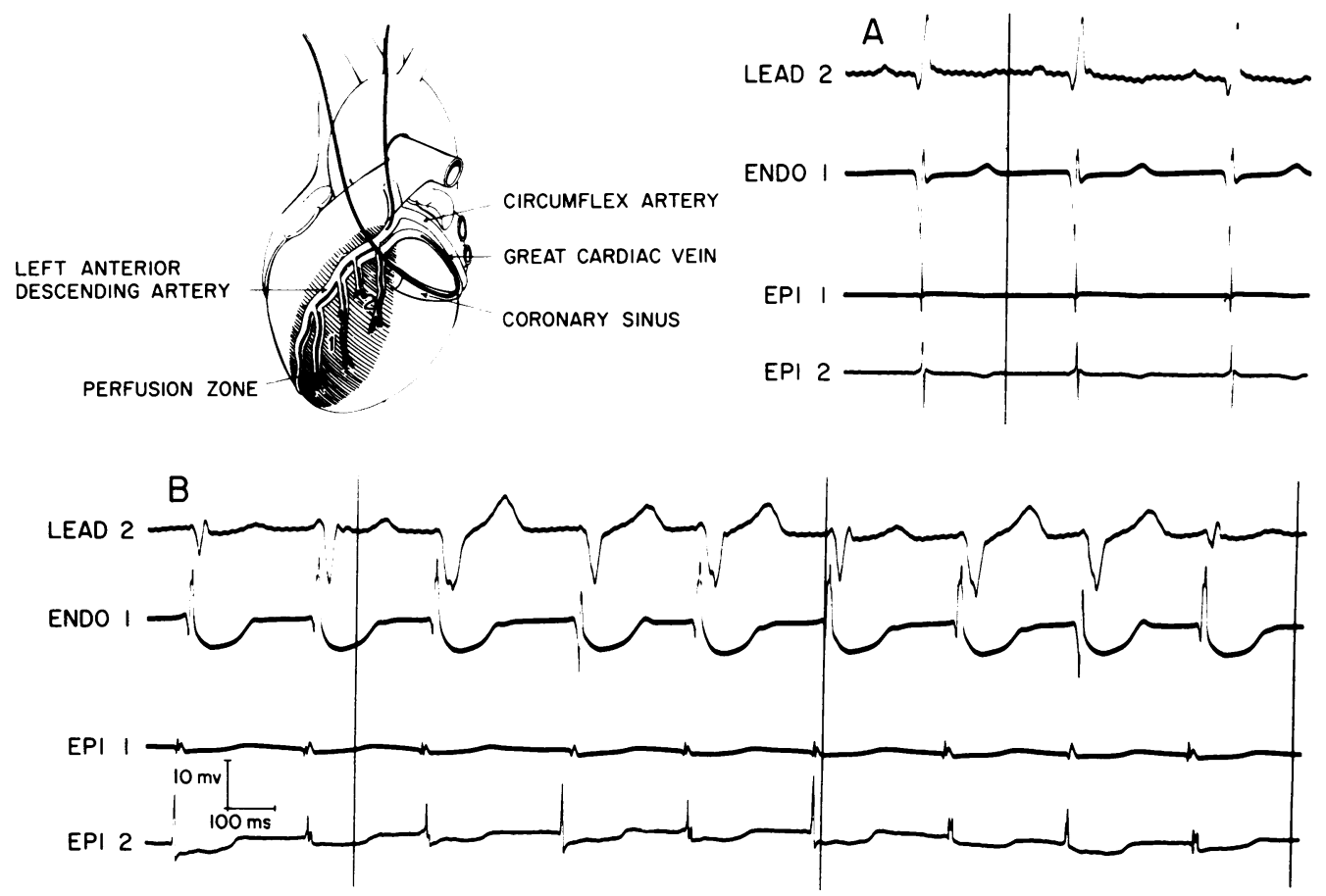

Figure 5 Early epicardial activation at two separate sites within the perfused zone, $2 \mathrm{~cm}$ apart. Diagram indicates electrode locations. At site one, both endocardial and epicardial electrodes are implanted; at site two, only epicardial. (A) Control. Both epicardial sites are activated 5-10 ms after endocardial activation at site one. (The endocardial electrogram is more slurred than usual.) (B) During arrhythmia, a 9-beat strip shows activation reversal at site one in every beat. In several beats $(1,4,8)$, however, activation of epicardium at site two even precedes epicardial activation at site one, although both precede onset of QRS. Early epicardial activation is most easily seen in beat 6, where a time line fortuitously marks the onset of QRS. 


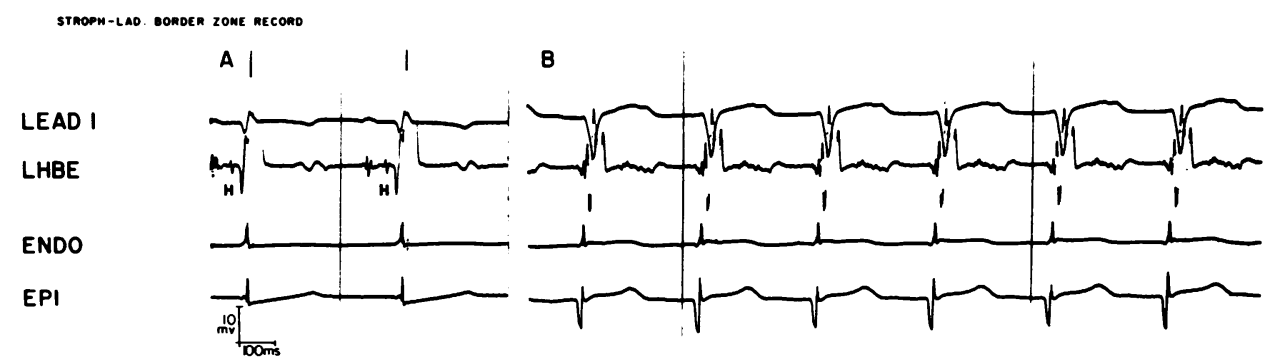

D
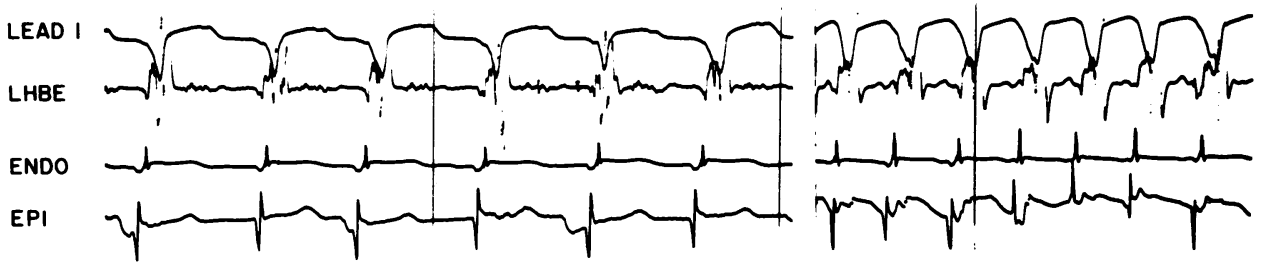

Figure 6 Border zone record, Group 3 animal. (A) Control. (B, C, and D) During progressively increasing rate with ventricular tachycardia of varying morphology. Epicardial electrograms precede endocardial; however, they do not precede QRS onset. Abbreviations, paper speed, and calibrations as before.

in this model, although long sequences of beats showing only minor configurational differences, as in Figs. 4 and 5, were often seen.

Of the 10 dogs of Group 3, 3 were border area studies, in which 2 of the 3 demonstrated epicardialendocardial reversal (Fig. 6). None of the seven circumflex region studies showed this (Fig. 7).

Electrolyte changes in myocardium. During the control period, arterial and great cardiac vein $\mathrm{K}^{+}$ values were similar (Table II). After the start of infusion, even before the onset of arrhythmia, a significant arteriovenous $\mathrm{K}^{+}$gradient had appeared at $2 \mathrm{~min}$, reached a maximum at $4 \mathrm{~min}$, and continued unabated until fibrillation. $\mathrm{K}^{+}$egress was accompanied by a decline in tissue $\mathrm{K}^{+}$of approximately $11 \%$ (approximately $8 \mu \mathrm{eq} / \mathrm{g}$ of myocardium, Table III) and a

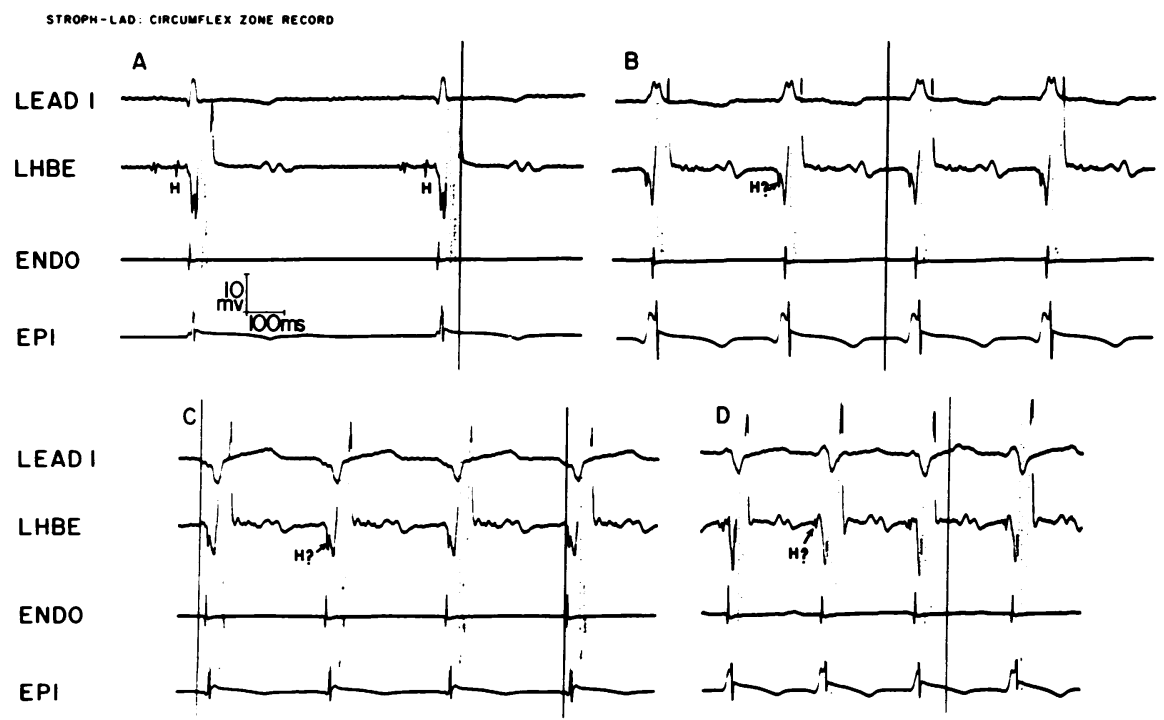

Figure 7 Circumflex zone recording (Group 3 animal). (A) Control. (B, C, and D) Sections showing ventricular tachycardia of differing morphology and with increasing heart rate. While some variation in the intramural electrogram morphology is seen, especially in B and D, the normal activation sequence of endocardium $\rightarrow$ epicardium is preserved. Abbreviations, paper speed, and calibrations as before. 
TABLE II

Coronary Venous $\mathrm{K}^{+}$Efflux during AS Infusion

\begin{tabular}{lccccccc}
\hline & \multicolumn{7}{c}{ Minutes of infusion* } \\
\cline { 2 - 9 } & 0 & 2 & 4 & 6 & 8 & 12 & 16 \\
\hline & & \multicolumn{7}{c}{ meq/liter } \\
Great cardiac & & & & & & & \\
$\quad$ vein & 3.30 & 3.89 & 4.38 & 4.16 & 4.22 & 4.23 & 4.18 \\
\pm SE & 0.07 & 0.14 & 0.16 & 0.14 & 0.19 & 0.25 & 0.19 \\
& & & & & & & \\
Arterial & 3.28 & 3.14 & 3.25 & 3.19 & 3.30 & 3.42 & 3.58 \\
\pm SE & 0.07 & 0.10 & 0.09 & 0.10 & 0.11 & 0.15 & 0.21 \\
$P \ddagger$ & NS & $<0.01$ & $<0.01$ & $<0.01$ & $<0.01$ & - & - \\
\hline & & &
\end{tabular}

* All arrhythmias began after $2 \mathrm{~min}$ but before $6 \mathrm{~min}$ of infusion.

t Probability (paired $t$ ). Numbers were too small for comparison $(5,4)$ at 12 and $16 \mathrm{~min}$.

similar rise in myocardial $\mathrm{Na}^{+}$. These tissue changes were homogeneous from epicardium to endocardium and were not observed in the circumflex (nonperfused) region. The mean $\mathrm{K}^{+}$loss and $\mathrm{Na}^{+}$gain in the perfused zone of Group 2 was greater in each layer than in Group 1. Border zone electrolytes were not obtained.

In 13 additional open-chest animals (Groups 4), $100 \mu \mathrm{g}$ AS $(0.2 \mathrm{ml}$, mixed with $0.1 \mathrm{ml}$ India ink) was injected into the left ventricular epicardial free wall from a tuberculin syringe with a 26-gauge needle. Two ECG leads and intramural epicardial and endocardial electrograms were recorded as before. Ventricular extrasystoles progressing to tachycardia began within 2-8 min, inducing arrhythmias similar to those induced by intracoronary infusion, with some variation in QRS configuration from beat to beat. Arrhythmias lasted from 4-8 min, subsiding slowly; ventricular fibrillation rarely resulted. Because the initial experiments involved continuous infusion to an end point of fibrillation, rate and duration of arrhythmias cannot be compared directly. In some animals, two to three different epicardial sites were injected sequentially and at measured distances from the electrodes. Six epicardial injections were made within $0.5 \mathrm{~cm}$ of the epicardial electrode; epicardial endocardial activation was observed in the majority of beats and preceded QRS onset during extrasystoles (Fig. 8). Normal endocardial $\rightarrow$ epicardial activation during arrhythmia followed epicardial injection at all locations $1.5-4 \mathrm{~cm}$ distant from electrodes in seven studies. Sections through the injection sites revealed subepicardial dye localization 5-7 $\mathrm{mm}$ wide and 3-5 $\mathrm{mm}$ deep. All but two attempts to inject into endocardial locations were unsuccessful because of failure to localize the dye in endocardium; in these studies,

TABLE III

Myocardial Electrolyte and Water Content

\begin{tabular}{|c|c|c|c|c|c|c|c|c|c|c|c|c|c|c|c|c|c|c|}
\hline & \multicolumn{9}{|c|}{ Left anterior descending zone (perfused) } & \multicolumn{9}{|c|}{ Circumflex zone (nonperfused) } \\
\hline & \multicolumn{3}{|c|}{$\mathbf{K}^{+}$} & \multicolumn{3}{|c|}{$\mathrm{Na}^{+}$} & \multicolumn{3}{|c|}{ Water } & \multicolumn{3}{|c|}{$\mathrm{K}^{+}$} & \multicolumn{3}{|c|}{$\mathrm{Na}^{+}$} & \multicolumn{3}{|c|}{ Water } \\
\hline & $\mathrm{Epi}^{*}$ & Mid & Endo & Epi & Mid & Endo & Epi & Mid & Endo & $\mathrm{E}_{\mathrm{pi}}$ & Mid & Endo & Epi & Mid & Endo & Epi & Mid & Endo \\
\hline & \multicolumn{3}{|c|}{$\mu e q / g$ wet ut } & \multicolumn{3}{|c|}{ meqlg wet ut } & \multicolumn{3}{|c|}{$\%$} & \multicolumn{3}{|c|}{ meq/g wet ut } & \multicolumn{3}{|c|}{ meqlg wet ut } & \multicolumn{3}{|c|}{$\%$} \\
\hline \multicolumn{19}{|l|}{$\begin{array}{l}\text { Group } 1 \\
\text { (VT) } \\
n=10\end{array}$} \\
\hline Mean & 63.2 & 68.0 & 62.8 & 38.8 & 39.2 & 40.2 & 79.2 & 78.2 & 78.6 & 69.6 & 72.9 & 68.8 & 30.3 & 33.0 & 34.8 & 78.2 & 78.5 & 78.0 \\
\hline$\pm \mathrm{SE}$ & 1.4 & 1.9 & 1.8 & 3.3 & 2.6 & 2.6 & 0.3 & 0.5 & 0.7 & 1.2 & 2.0 & 1.5 & 2.1 & 1.5 & 1.5 & 0.4 & 0.8 & 0.7 \\
\hline$P \downarrow$ & $<0.005$ & $<0.05$ & $<0.01$ & $<0.005$ & $<0.005$ & $<0.02$ & $\mathrm{NS}$ & $\mathrm{NS}$ & $\mathrm{NS}$ & & & & & & & & & \\
\hline \multicolumn{19}{|l|}{$\begin{array}{l}\text { Group } 2 \\
\text { (VF) } \\
n=11\end{array}$} \\
\hline Mean & 62.0 & 64.2 & 60.1 & 40.8 & 43.0 & 44.7 & 79.7 & 78.9 & 79.7 & 71.4 & 74.0 & 71.8 & 33.2 & 33.4 & 35.2 & 79.0 & 78.1 & 78.7 \\
\hline$\pm \mathrm{SE}$ & 1.9 & 1.8 & 1.3 & 2.0 & 1.5 & 2.6 & 0.4 & 0.4 & 0.3 & 1.4 & 1.9 & 1.5 & 2.4 & 1.4 & 1.9 & 0.5 & 0.6 & 0.5 \\
\hline$P$ & $<0.005$ & $<0.001$ & $<0.001$ & $<0.001$ & $<0.001$ & $<0.001$ & NS & $\mathrm{NS}$ & NS & & & & & & & & & \\
\hline \multicolumn{19}{|c|}{$\begin{array}{l}\text { All (VT } \\
\text { and VF) } \\
n=21\end{array}$} \\
\hline Mean & 62.6 & 66.0 & 61.4 & 39.9 & 41.2 & 42.6 & 79.5 & 78.6 & 79.2 & 70.5 & 73.5 & 70.4 & 31.9 & 33.2 & 35.0 & 78.6 & 78.3 & 78.4 \\
\hline$\pm \mathrm{SE}$ & 1.2 & 1.3 & 1.1 & 1.9 & 1.5 & 1.9 & 0.3 & 0.3 & 0.4 & 0.9 & 1.4 & 1.1 & 1.6 & 1.0 & 1.2 & 0.3 & 0.5 & 0.4 \\
\hline$P$ & $<0.001$ & $<0.001$ & $<0.001$ & $<0.001$ & $<0.001$ & $<0.001$ & NS & NS & NS & & & & & & & & & \\
\hline \multicolumn{19}{|l|}{$\begin{array}{c}\text { Controlई } \\
n=12\end{array}$} \\
\hline Mean & 72.0 & 73.6 & 68.9 & 32.3 & 35.5 & 35.3 & 78.9 & 78.8 & 79.7 & 72.7 & 71.0 & 70.5 & 31.8 & 32.9 & 33.7 & 79.0 & 79.3 & 79.2 \\
\hline$\pm \mathrm{SE}$ & 1.1 & 1.2 & 1.6 & 1.0 & 1.1 & 1.5 & 0.3 & 0.6 & 0.4 & 1.7 & 1.3 & 1.6 & 1.2 & 1.0 & 0.9 & 0.4 & 0.3 & 0.3 \\
\hline
\end{tabular}

$V F$, ventricular fibrillation; VT, ventricular tachycardia.

* Epi, mid, and endo refer to outer, middle, and inner thirds of left ventricular wall.

I $P$ values in columns reflecting the left anterior descending zone compare individual lavers with the same layer in circumflex zone, in the same animals. The circumflex zone showed no significant differences with either zone in controls.

$\S$ Neither area was perfused in control animals. 
both distant from the electrodes, normal (outward) ventricular activation was observed during ventricular tachycardia.

\section{DISCUSSION}

Ectopic cardiac electrical activity begins in a limited region and absolute identification of this region requires multiple electrical recording points in three dimensions. Certain minimum conditions could be stipulated, however, necessary although not sufficient for proof of the assumption that arrhythmias may arise at an intramural site. First, activation should occur in the suspected area of myocardium before surface QRS activity, recognizing that even in normals some mural activation occurs $10-20 \mathrm{~ms}$ before the onset of the surface QRS. Second, activation should involve endocardium at that point after the middle or outer wall. Third, activation of the nearby endocardial Purkinje network and the His bundle should follow transmural activation at that site. All of these conditions are met by the arrhythmias observed, although our evidence is not definitive proof of the origin of digitalis arrhythmias.

Our conclusions contrast with prior investigations of digitalis arrhythmias in the dog $(1,8)$. Epicardial mapping of unifocal ventricular tachycardia after systemic ouabain or AS was used in one (1) to locate the point of earliest epicardial breakthrough; plunge electrode studies there indicated endocardial to epicardial activation, suggesting endocardial (probably Purkinje) origin. Possibly systemic administration induced earliest automaticity in the subendocardial Purkinje network, whereas (in our study) direct coronary artery perfusion beyond the origin of the septal artery reached the left ventricular wall muscle preferentially. In another (8), left bundle branch activity preceded QRS during systemic digitalis toxicity, also suggesting that the arrhythmias arose in the distal Purkinje net. We also observed (Figs. 3, 4) left bundle branch impulses at least simultaneous with QRS onset, but our intramural recordings (Figs. 4, 5) indicate even earlier electrical activity within the wall.

Transmural activation reversals observed with AS perfusion might have been attributed to abnormal propagation sequences within a region depressed by it. Such anomalies are observed within and at the borders of infarction $(19,20)$. However, evidence for significant conduction depression or electrogram voltage change during drug perfusion was not observed, and electrograms of intermittently conducted sinus beats during the ventricular tachycardia were unchanged. A similar alternative possibility is that arrhythmias arose in the inner wall or endocardial Purkinje network and our recordings reflect exit block affecting the normal conduction pathways.
A

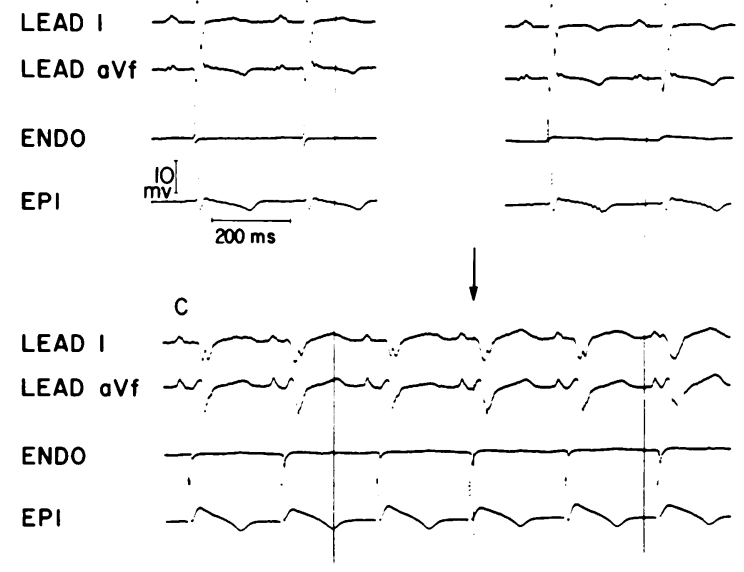

Figure 8 Recording from LAD zone before (A), $30 \mathrm{~s}$ after (B) and $5 \mathrm{~min}$ after (C) intramyocardial injection of AS into region of the epicardial electrode. Modest reduction of electrogram amplitude is evident in $\mathrm{B}$. In $\mathrm{C}$, a ventricular arrhythmia is present although by chance the rate is similar (in this instance) to sinus ( $\mathrm{P}$-wave) rate. During the tachycardia, epicardial activation precedes endocardial, and both precede onset of QRS (see arrow) in all beats. The endocardial electrogram is reversed in polarity, possibly substantiating activation from the opposite direction, i.e., epi $\rightarrow$ endo. Abbreviations, paper speed, and calibrations as before.

Depolarization of the perfused region might then occur via muscle from nonperfused border zones, thus accounting for the inward spread of activation. Both explanations require an endocardial focus firing extremely early. Figs. 4 and 5 indicate epicardial depolarization in the perfused zone $16 \mathrm{~ms}$ before QRS onset; these would require a hypothetical endocardial activation to have occurred many milliseconds earlier. We think this unlikely and our view is supported by the similar electrograms obtained during subepicardial injection of AS.

While it might be assumed that early epicardial activation should have been seen consistently from the moment of onset of arrhythmia if the origin was truly in the outer wall, such observation would be likely only if the initial point of origin had been immediately adjacent to the electrodes. It is perhaps more likely that arrhythmias arose at first distant from the electrodes, as the latter were arbitrarily placed within the large anterior descending zone. As perfusion continued, however, a larger and larger region became involved in arrhythmia generation, eventually encompassing the electrode site. It is unlikely that recordings made at a single point on the ventricular wall would be so frequently close ( 8 of 11 cases) to any unifocal arrhythmic locus; rather, a broad region (Fig. 5) became capable of producing extra beats. 
TABLE IV

Comparison of Digitalis Effects after Intracoronary or Intravenous Administration*

\begin{tabular}{|c|c|c|}
\hline & Intracoronary & Intravenous \\
\hline Dosage of AS & $25 \mu \mathrm{g} / \mathrm{min}$ into LAD artery $(\sharp)$ & $50 \mu \mathrm{g} / \mathrm{kg}$ i.v. single dose (38) \\
\hline Effect on S-A node & None $(\$, 39)$ & Slows rate $(17,18)$ \\
\hline Effect on A-V conduction & None $(\$)$ & Slows conduction through $\mathrm{A}-\mathrm{V}$ node \\
\hline $\begin{array}{l}\text { Ventricular tachycardia } \\
\text { Onset }\end{array}$ & $2-6 \min (\$)$ & $2-6 \min (38)$ \\
\hline Duration & $\begin{array}{l}\text { Fibrillates } 2-20 \text { min after } \\
\text { onset of infusion ( }()\end{array}$ & $\begin{array}{l}\text { 1-5 min if no additional drug given; } \\
\text { continues with additional drug (38) }\end{array}$ \\
\hline Rate & $\begin{array}{l}\text { Progressive increase until } \\
\text { ventricular fibrillation ( } \downarrow)\end{array}$ & $\begin{array}{l}\text { Maximum after } 1-5 \mathrm{~min} \text {, then slows } \\
\text { without further drug (38) }\end{array}$ \\
\hline Morphology & $\begin{array}{l}\text { Usually multiform, some- } \\
\text { times unifocal; intermit- } \\
\text { tent sinus and fusion beats } \\
\text { seen }(\ddagger)\end{array}$ & Often unifocal (38) \\
\hline Autonomic effects & No data & $\begin{array}{l}\text { Fibrillation and ventricular tachycardia } \\
\text { related in part to drug-induced sympa- } \\
\text { thetic activity }(40,41)\end{array}$ \\
\hline $\begin{array}{l}\text { Pacemaker site during } \\
\text { ventricular tachycardia }\end{array}$ & Possibly intramural ( $\ddagger$ ) & $\begin{array}{l}\text { Possibly from endocardial Purkinje net- } \\
\text { work }(1,8) \text {; mainly left ventricular } \\
\text { origin in dog (1). Intramural origin not } \\
\text { ruled out. }\end{array}$ \\
\hline
\end{tabular}

* Other investigators referenced; results in this study are indicated by $\$$. Data given are for AS where available $(38,39)$, otherwise for ouabain.

We cannot determine whether automaticity or reentry is responsible for the arrhythmias. The absence of significant conduction delay and the infrequency of electrogram slurring suggest that reentry is unlikely although limited regions of reentry cannot be excluded. Yet the absence of known potential pacemaker cells in the outer wall do not allow easy interpretation of the arrhythmias as automatic, either. Scher and Young $(21,22)$ concluded that there was no evidence for Purkinje fiber penetration in dogs beyond 1-2 $\mathrm{mm}$ from the endocardial surface in those portions of the free wall not overlying the papillary muscles. Although disputed in part by others (23-25), more recent work (26) tends to confirm this view. Our findings suggest potentially automatic cells within the ventricular wall, although the nature of these cells cannot now be ascertained.

Extrasystoles that arise within the perfused region should activate the remainder of the myocardium by a combination of contiguous intramural excitation and by more rapid spread to distant regions via the subendocardial Purkinje network. Activation was sometimes abnormal at the borders but was normal at distant points (Group 3), presumably because at distant points (Fig. 7) excitation arrives first via the Purkinje network $(21,27)$.
The unifocal ventricular tachycardia seen after systemic administration of digitalis and manifested by unvarying morphology of QRS was not observed here, where individual beats resembled each other but were usually not identical. In addition, ventricular capture by sinus impulses and typical fusion beats were seen. These differences (Table IV) may be explained by factors that favor development of unifocal arrhythmias after systemic digitalis. Sinus node slowing, often of profound degree, occurs regularly with systemic glycoside $(17,18)$ along with atrioventricular conduction delay, the latter delaying or preventing antegrade conduction. With intracoronary administration of drug, sinus slowing and A-V conduction delay did not occur; thus, ventricular capture by conducted sinus impulses as well as varying degrees of fusion were frequently observed. Additional causes of nonuniformity of QRS morphology during tachycardia may have been real beat-to-beat variations in the actual site(s) of arrhythmia production and in depolarization sequence. Innumerable variations of wavefront spread from myocardial foci seem likely in contrast to foci within the Purkinje network where a limited, repetitive activation sequence might be imposed by the anatomy of the network itself. In either case, increased temporal dispersion of recovery times 
induced by digitalis (28) may facilitate wavefront fractionation and fibrillation.

While myocardial $\mathrm{K}^{+}$loss during digitalization has been repeatedly demonstrated in animals (29-34) and man (35), the uniformity of digitalis-induced transmural electrolyte changes demonstrated here represent new observations. These contrast with the transmural ionic gradients we observed after ischemia (36) and after regional infusions of $\mathrm{K}^{+}(11)$ or epinephrine (36) into the canine coronary artery, all of which induced electrolyte changes in which $\mathrm{K}^{+}$was lower and $\mathrm{Na}^{+}$higher in endocardial layers as compared with epicardial. Cellular $\mathrm{K}^{+}$loss after AS raises the $\mathrm{K}_{\mathrm{o}} / \mathrm{K}_{\mathrm{i}}$ ratio, a change known to be associated with arrhythmia during both ischemia (37) and local coronary artery infusion of $\mathrm{KCl}$ (11). Under these conditions arrhythmogenesis would be most likely either in the most intensely $\mathrm{K}^{+}$depleted region or where electrolyte gradients are steepest. It remains unclear why the outer wall should appear to generate arrhythmias in our study, since the severity of $\mathrm{K}^{+}$loss there was not greater than in endocardium. However, it is difficult to interpret our findings of early epicardial depolarization and activation reversal as indicating other than an intramural origin of the arrhythmias in this model.

\section{ACKNOWLEDGMENTS}

The technical assistance of B. Jenkins, R. Moore, R. Nowak, F. Herdman, and R. Torres, and the secretarial services of A. Binetti and A. Brown are gratefully acknowledged.

This investigation was supported, in part, by research grant HL 09914 and postgraduate training grant HL 05510 from the National Heart, Lung, and Blood Institute, National Institutes of Health and by a research grant from the American Heart Association, New Jersey Affiliate.

\section{REFERENCES}

1. Kastor, J. A., J. F. Spear, and E. N. Moore. 1972. Localization of ventricular irritability by epicardial mapping. Origin of digitalis-induced unifocal tachycardia from left ventricular Purkinje tissue. Circulation. 45: 952-964.

2. Durrer, D., and J. P. Roos. 1967. Epicardial excitation of the ventricles in a patient with Wolff-ParkinsonWhite syndrome (type B). Circulation. 35: 15-21.

3. Burchell, H. B., R. L. Frye, M. W. Anderson, and D. C. McGoon. 1967. Atrioventricular and ventriculoatrial excitation in Wolff-Parkinson-White syndrome (type B). Temporary ablation at surgery. Circulation. 36: 663672.

4. Cobb, F. R., S. D. Blumenschein, W. C. Sealy, J. P. Boineau, G. S. Wagner, and A. G. Wallace. 1968. Successful surgical interruption of the Bundle of Kent in a patient with Wolff-Parkinson-White syndrome. Circulation. 38: 1018-1029.

5. Dudel, J., and W. Trautwein. 1958. Elektrophysiologische Messungen zur Strophanthinwirkung am Herzmuskel.
Naunyn-Schmiedebergs Arch. Pharmakol. Exp. Pathol. 232: 393-407.

6. Vassalle, M., J. Karis, and B. F. Hoffman. 1962. Toxic effects of ouabain on Purkinje fibers and ventricular muscle fibers. Am. J. Physiol. 203: 433-439.

7. Hoffman, B. F., and D. H. Singer. 1964. Effects of digitalis on electrical activity of cardiac fibers. Prog. Cardiovasc. Dis. 7: 226-260.

8. Damato, A. N., S. H. Lau, and G. A. Bobb. 1971. Digitalis-induced bundle-branch ventricular tachycardia studied by electrode catheter recordings of the specialized conducting tissues of the dog. Circ. Res. 28: 16-22.

9. Ross, S. M., and B. F. Hoffman. 1960. A bipolar pacemaker for immediate treatment of cardiac arrest. $J$. Appl. Physiol. 15: 974-976.

10. Scherlag, B. J., B. D. Kosowsky, and A. N. Damato. 1967. A technique for ventricular pacing from the His bundle of the intact heart. J. Appl. Physiol. 22: 584-587.

11. Ettinger, P. O., T. J. Regan, H. A. Oldewurtel, and M. I. Khan. 1973. Ventricular conduction delay and arrhythmias during regional hyperkalemia in the dog. Electrical and myocardial ion alterations. Circ. Res. 33: 521-531.

12. Ettinger, P. O., M.I. Khan, and T. J. Regan. 1970. A catheter electrode technique for study of left ventricular conduction. J. Appl. Physiol. 28: 519-523.

13. Scherlag, B. J., J. Abelleira, and P. Samet. 1969. Recording from the His bundle and left bundle branches during left heart catheterization in dogs. Circulation. 40 (Suppl. III): III-179. (Abstr.)

14. Narula, O. S., R. P. Javier, P. Samet, and L. C. Maramba. 1970. Significance of $\mathrm{His}$ and left bundle recordings from the left heart in man. Circulation. 42: 385-396.

15. Isreeli, J., M. Pelavin, and G. Kessler. 1960. Continuous automatic integrated flame photometry. Ann. N. Y. Acad. Sci. 87: 636-649.

16. Regan, T. J., G. Koroxenidis, C. B. Moschos, H. A. Oldewurtel, P. H. Lehan, and H. K. Hellems. 1966. The acute metabolic and hemodynamic responses of the left ventricle to ethanol. J. Clin. Invest. 45: 270-280.

17. Vassalle, M., K. Greenspan, and B. F. Hoffman. 1963. An analysis of arrhythmias induced by ouabain in intact dogs. Circ. Res. 13: 132-148.

18. Scherlag, B. J., J. L. Abelleira, O. S. Narula, and P. Samet. 1971. The differential effects of ouabain on sinus, A-V nodal, His bundle and idioventricular rhythms. Am. Heart J. 81: 227-235.

19. Waldo, A. L., G. A. Kaiser, R. J. Castany, and B. F. Hoffman. 1968. A study of arrhythmias associated with acute myocardial infarction. Circulation. 38:200.

20. Boineau, J. P., and J. L. Cox. 1973. Slow ventricular activation in acute myocardial infarction. A source of re-entrant premature ventricular contractions. Circulation. 48: 702-713.

21. Scher, A. M., and A. C. Young. 1955. Spread of excitation during premature ventricular systoles. Circ. Res. 3: $335-342$.

22. Scher, A. M., and A. C. Young. 1957. Ventricular depolarization and the genesis of QRS. Ann. N. Y. Acad. Sci. 65: 768-778.

23. Durrer, D., and L. H. van der Tweel. 1957. Excitation of the left ventricular wall of the dog and goat. Ann. N. Y. Acad. Sci. 65: 779-803.

24. Medrano, G. A., A. Bisteni, R. W. Brancato, F. Pileggi, and D. Sodi-Pallares. 1957. The activation of the 
interventricular septum in the dog's heart under normal conditions and in bundle-branch block. Ann. N. Y. Acad. Sci. 65: 804-817.

25. Sodi-Pallares, D., and R. M. Calder. 1956. New Bases of Electrocardiography. The C. V. Mosby Co., St. Louis, Mo. 727 pp.

26. Selvester, R. H., W. L. Kirk, Jr., and R. B. Pearson. 1970. Propagation velocities and voltage magnitudes in local segments of dog myocardium. Circ. Res. 27: 619-629.

27. Lewis, T. 1915. The excitatory process in the dog's heart. II. The ventricles. Proc. R. Soc. Lond. B. Biol. Sci. 206: 181-226.

28. Han, J., and G. K. Moe. 1964. Nonuniform recovery of excitability in ventricular muscle. Circ. Res. 14: 4460.

29. Calhoun, J. A., and T. R. Harrison. 1931. Studies in congestive heart failure. IX. The effect of digitalis on the potassium content of the cardiac muscle of dogs. J. Clin. Invest. 10: 139-144.

30. Wedd, A. M. 1939. Influence of digoxin on potassium content of heart muscle. J. Pharmacol. Exp. Ther. 65: 268-274.

31. Wood, E. H., and G. K. Moe. 1942. Blood electrolyte changes in the heart-lung preparation with special reference to the effects of cardiac glycosides. Am. J. Physiol. 137: 6-21.

32. Regan, T. J., F. N. Talmers, and H. K. Hellems. 1956. Myocardial transfer of sodium and potassium: Effect of acetyl strophanthidin in normal dogs. $J$. Clin. Invest. 35: 1220-1228.

33. Cairns, A. B., Jr., W. D. Love, and G. E. Burch. 1960. The effects of acetyl-strophanthidin on the kinetics of potassium and $\mathbf{R b}^{\mathbf{8 6}}$ in the myocardium of dogs. Am. Heart J. 59: 404-411.
34. Sarnoff, S. J., J. P. Gilmore, J. H. Mitchell, and J. P. Remensnyder. 1963. Potassium changes in the heart during homeometric autoregulation and acetyl strophanthidin. Am. J. Med. 34: 440-451.

35. Hellems, H. K., T. J. Regan, F. N. Talmers, R. C. Christensen, and T. Wada. 1956. The mode of action of acetyl strophanthidin on the failing human heart. J. Clin. Invest. 35: 710. (Abstr.)

36. Regan, T. J., A. Markov, M. I. Khan, M. U. Jesrani, H. A. Oldewurtel, and P. O. Ettinger. 1972. Myocardial ion and lipid changes during ischemia and catecholamine induced necrosis: Relation to regional blood flow. In Myocardiology: Recent Advances in Studies on Cardiac Structure and Metabolism. E. Bajusz, and G. Rona, editors. University Park Press, Baltimore, Md. 1: 656664.

37. Regan, T. J., M. A. Harman, P. H. Lehan, W. M Burke, and H. A. Oldewurtel. 1967: Ventricular arrhythmias and $\mathrm{K}^{+}$transfer during myocardial ischemia and intervention with procaine amide, insulin or glucose solution. J. Clin. Invest. 46: 1657-1668.

38. Regan, T. J., B. L. London, K. Binak, and H. K. Hellems. 1962. Sympathomimetics as antagonists of strophanthidin's ionic and arrhythmic effects. Circ. Res. 11: 17-25.

39. Hood, W. B., Jr., B. Letac, G. Roberg, and B. Lown. 1968. Director digitalization of the myocardium. Hemodynamic effects. Am. J. Cardiol. 22: 667.

40. Gillis, R. A. 1969. Cardiac sympathetic nerve activity: changes induced by ouabain and propranolol. Science (Wash. D. C.). 166: 508-510.

41. Gillis, R. A., A. Raines, Y. B. Levitt, and F. G. Standaert. J. Sohn, 1972. Neuroexcitatory effects of digitalis and their role in the development of cardiac arrhythmias. J. Pharmacol. Exp. Ther. 183: 154-168. 